\title{
Development of Thermal Barrier Coating System with Superior Thermal Cyclic Properties with an Intermediate Layer Containing $\mathrm{MoSi}_{2}$
}

\author{
Keiji SONOYA $^{* *}$ and Shogo TOBE ${ }^{* * *}$ \\ **University of Yamanashi, \\ 4-3-11 Takeda, Kofu, Yamanashi, 400-8511, Japan \\ E-mail: ksonoya@yamanashi.ac.jp \\ ***Ashikaga Institute of Technology,
}

268-1 Omae-Cho, Ashikaga City, Tochigi, 326-8558, Japan

\begin{abstract}
The authors have developed a method of improving the thermal cyclic resistance of the thermal barrier coating system that is deposited on gas turbine components. A conventional thermal barrier coating consists of a duplex system: a top coating and a bond coating. The developed system has a protective intermediate layer of $\mathrm{MoSi}_{2}$ which prevents oxidation of the bond coating. The conventional duplex plasma -sprayed coating was delaminated after 20 thermal cycles. On the other hand, the developed triple-layered coating system was not delaminated after 60 cycles. The reason for the enhanced resistance to thermal cycles of the developed triple- layered coating system is that the $\mathrm{MoSi}_{2}$ layer between the top coating and the bond coating has a self-repairing property. $\mathrm{MoSi}_{2}$ oxidizes to form $\mathrm{SiO}_{2}$, which seals the cracks and pores formed between the top coating and the bond coating. Thus, the formation of a thermally grown oxide(TGO), which causes the delamination of the coating, is prevented and the thermal cyclic resistance is improved.
\end{abstract}

Key words: Thermal Barrier Coating, Oxidation, Thermal Cyclic Resistance, TGO, $\mathrm{MoSi}_{2}$

\section{Introduction}

Nonutility power generation facilities are regularly used as co-generation systems, in which the waste heat produced from electricity generation is recycled as steam. Recently, gas turbines have been increasingly used instead of steam turbines, because of their superior characteristics such as compactness, light weight, and their clean waste gas.

Many approaches have been taken to increase the output and energy conversion efficiency of gas turbines and reduce their environmental load. One approach is to increase the operating temperature. The operating temperature of gas turbines can be increased by applying a thermal barrier coating (TBC) to the blades and vanes of the gas turbine ${ }^{(1),(2)}$. A conventional TBC usually consists of a ceramic- $\mathrm{M}(\mathrm{Co}, \mathrm{Ni}) \mathrm{CrAlY}$ duplex coating. The ceramic top coating consists of partially stabilized zirconia $\left(\mathrm{ZrO}_{2}+8 \% \mathrm{Y}_{2} \mathrm{O}_{3}\right.$ : YSZ) which has low thermal conductivity. MCrAlY acts as a bond coating between the top ceramic coating and the superalloy substrate. A thermally grown oxide (TGO) is frequently formed between the bond coating and the top coating during the high- temperature operation of the gas turbine. Cracking tends to occur near the TGO surface, causing delamination of the 
ceramic $\mathrm{TBC}^{(3)}$ as a result of the induced thermal stress. Therefore, the growth of the TGO reduces the thermal cyclic resistance of the TBC and eventually causes failure.

A triple-layered TBC system has been developed to enhance the thermal cyclic performance by introducing an intermediate layer of $\mathrm{MoSi}_{2}$ between the top ceramic coating and the bond coating in the conventional TBC system. $\mathrm{MoSi}_{2}{ }^{(4)}$ has a self-repairing characteristic owing to the formation of $\mathrm{SiO}_{2}$ within cracks. The triple-layered coating is expected to prevent the formation of TGO on the MCrAlY coating surface by preventing oxidation of the bond coating subsequently increasing the thermal cyclic resistance of the $\mathrm{TBC}$

In this study, with the aim of applying the developed $\mathrm{TBC}$ to gas turbines, the properties of the developed TBC compared with the conventional TBC were investigated, and the mechanism by which thermal cyclic resistance is improved was considered.

\section{Experimental procedures}

\subsection{Specimens}

A cobalt-based superalloy of $\mathrm{Co}-25 \% \mathrm{Cr}-10 \% \mathrm{Ni}-7.5 \% \mathrm{~W}$ was used as a substrate. The bond coating was a NiCrAlY alloy with the nominal composition of $\mathrm{Ni}-21 \% \mathrm{Cr}-8 \% \mathrm{Al}-0.5 \% \mathrm{Y}$. A YSZ ceramic was used as the top coating material.

Table 1 Details of materials used in tests

\begin{tabular}{|c|c|c|c|c|c|}
\hline Materials & Coating A & Coating B & $\begin{array}{c}\text { Coating } \mathrm{C} \\
\text { (Conventional) }\end{array}$ & $\begin{array}{c}\text { Coating D } \\
\text { (Developed) }\end{array}$ & Coating E \\
\hline $\begin{array}{c}\text { Bond coating } \\
(150 \mu \mathrm{m})\end{array}$ & $\begin{array}{l}\text { NiCrAlY } \\
\text { (LPPS*) }\end{array}$ & $\begin{array}{c}\text { NiCrAlY } \\
\text { (LPPS) }\end{array}$ & $\begin{array}{c}\text { NiCrAlY } \\
\text { (LPPS) }\end{array}$ & $\begin{array}{c}\text { NiCrAlY } \\
\text { (LPPS) }\end{array}$ & $\begin{array}{c}\text { NiCrAlY } \\
\text { (LPPS) }\end{array}$ \\
\hline $\begin{array}{c}\text { Intermediate } \\
\text { layer coating } \\
(100 \mu \mathrm{m})\end{array}$ & $\begin{array}{c}\mathrm{MoSi}_{2} \\
+\mathrm{YSZ} \\
(\mathrm{APS} * *)\end{array}$ & $\begin{array}{l}\mathrm{MoSi}_{2} \\
\text { (APS) }\end{array}$ & - & $\begin{array}{c}\mathrm{MoSi}_{2} \\
+\mathrm{NiCrAlY} \\
\text { (LPPS) }\end{array}$ & - \\
\hline $\begin{array}{l}\text { Top coating } \\
(150 \mu \mathrm{m})\end{array}$ & $\begin{array}{c}\text { YSZ } \\
\text { (APS) }\end{array}$ & $\begin{array}{l}\text { YSZ } \\
\text { (APS) }\end{array}$ & $\begin{array}{l}\text { YSZ } \\
\text { (APS) }\end{array}$ & $\begin{array}{c}\text { YSZ } \\
\text { (APS) }\end{array}$ & $\begin{array}{c}\mathrm{YSZ} \\
+\mathrm{MoSi}_{2} \\
\text { (APS) }\end{array}$ \\
\hline
\end{tabular}

* LPPS: Low-Pressure Plasma Spraying ** APS: Atmospheric-Pressure Plasma Spraying

The intermediate $\mathrm{MoSi}_{2}$ layer was introduced between the bond coating and the top coating to enhance the oxidation resistance of the system.

\subsection{Preparation of coatings}

The substrate with dimensions of $100 \times 40 \times 5 \mathrm{~mm}$ was blasted with \#24 alumina grit before spraying. For the duplex-layer TBC specimens, the NiCrAlY bond coating was deposited with a thickness of $150 \mu \mathrm{m}$ on the substrate before the deposition of the top coating. For the triple-layered TBC specimens, after the deposition of the bond coating on the substrate, the intermediate $\mathrm{MoSi}_{2}$ layer was deposited with a thickness of $100 \mu \mathrm{m}$ on the bond coating surface, and then the top YSZ coating was sprayed on the $\mathrm{MoSi}_{2}$ layer surface. All coatings were deposited either by atmospheric-pressure plasma spraying (APS) or by low-pressure plasma spraying (LPPS). The conditions of APS were as follows: power $35 \mathrm{~V}$, current $800 \mathrm{~A}$, working gas $\mathrm{Ar}$ at $0.35 \mathrm{MPa}$, auxiliary gas $\mathrm{He}$ at $0.28 \mathrm{MPa}$, and spraying distance $100 \mathrm{~mm}$. The conditions of LPPS were as follows: power $35 \mathrm{~V}$, current $700 \mathrm{~A}$, working gas Ar at $0.35 \mathrm{MPa}$, auxiliary gas $\mathrm{He}$ at $0.28 \mathrm{MPa}$, spraying distance $200 \mathrm{~mm}$, 

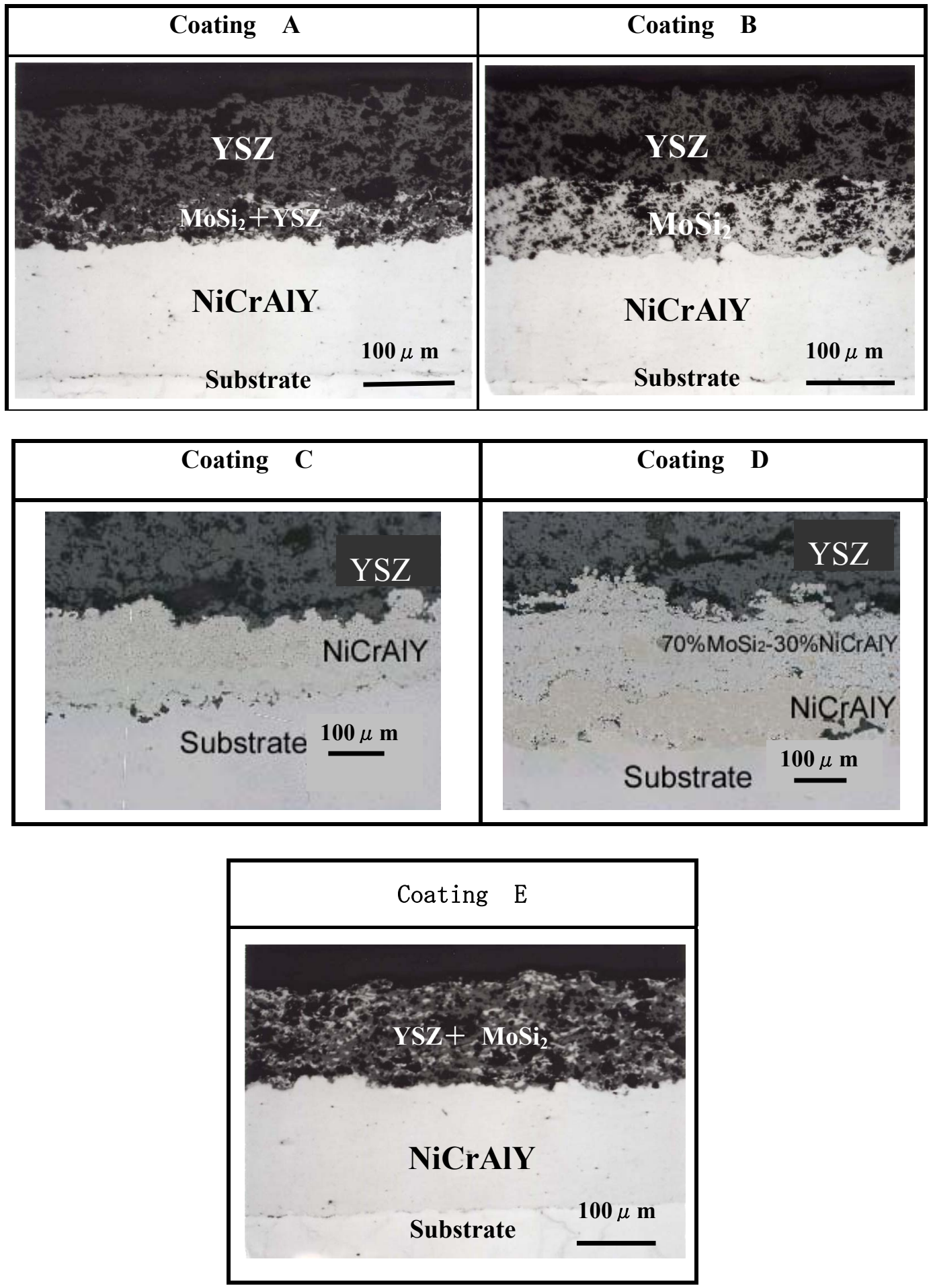

Fig. 1 Cross-sectional SEM images of coatings used

and chamber pressure 50 torr for the five types of TBC specimens, which had different combinations of coatings. The constituents of all specimens are shown in Table 1. YSZ coatings were deposited by APS, and NiCrAlY coatings were deposited by LPPS to reduce alloy oxidation during spraying. Coating A shown in Table 1 consisted of an intermediate layer containing $\mathrm{MoSi}_{2}$ and YSZ, which was deposited by APS using a mechanically blended composite powder of $\mathrm{MoSi}_{2}$ and YSZ with a weight ratio of 3:7. Coating D in Table 1 contained the intermediate layer deposited by LPPS using a composite powder of $\mathrm{MoSi}_{2}$ and NiCrAlY with a weight ratio of 7:3 to improve the ductility of the coating. The top 
coating of coating E was deposited by APS using a composite powder mixture of $\mathrm{MoSi}_{2}$ and YSZ with a weight ratio of $3: 7$. In the case of the coating sprayed by APS using a composite powder of $\mathrm{MoSi}_{2}$ and YSZ, the microstructure becomes optimum at a weight ratio of 3:7, because the microstructure is most dense at this ratio. Therefore, a composite powder mixture of $\mathrm{MoSi}_{2}$ and $\mathrm{YSZ}$ with a weight ratio of 3:7 was selected. In the case of the coating sprayed by LPPS using a composite powder of $\mathrm{MoSi}_{2}$ and $\mathrm{NiCrAlY}$, we found that the thermal cyclic property becomes optimum at a weight ratio of 7:3. Therefore, a composite powder mixture of $\mathrm{MoSi}_{2}$ and NiCrAlY with a weight ratio of 7:3 was selected. Typical SEM images of coatings A-E are shown in Fig. 1. Deposited thicknesses of top coating, intermediate coating and bond coating were target values respectively.

\subsection{Thermal cyclic tests}

The dimensions of each specimen used for the thermal cyclic tests were $40 \times 40 \times 5 \mathrm{~mm}$. In the tests, the sample was heated in a furnace at $1273 \mathrm{~K}$ for $2 \mathrm{~h}$, and then naturally cooled in ambient atmosphere for $10 \mathrm{~min}$ to induce thermal strain. The delamination characteristics of the coatings with increasing number of test cycles were examined.

The time at which delamination of over $10 \mathrm{~mm}^{2}$ occurred on the surface of the coating was defined as the delamination lifetime on the basis of our previous experiancs. An example of the delamination of coating $\mathrm{C}$ is shown in Fig. 2.

\subsection{Self-repairing tests on precracks}

$\mathrm{MoSi}_{2}$ exhibits a self-repair characteristic through the formation of $\mathrm{SiO}_{2}$ during its oxidation $^{(4)}$. This self-repair characteristic was investigated. A composite powder of $\mathrm{MoSi}_{2}$ and NiCrAlY with a weight ratio of 7:3 was sprayed as the bond coating on substrates $(100 \times 40 \times 5 \mathrm{~mm})$ by LPPS.

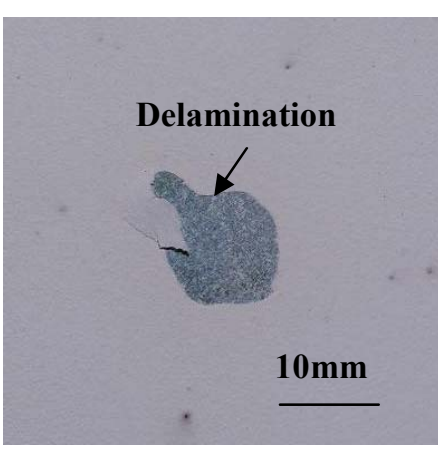

(a) Delamination on the surface of thermally sprayed coating

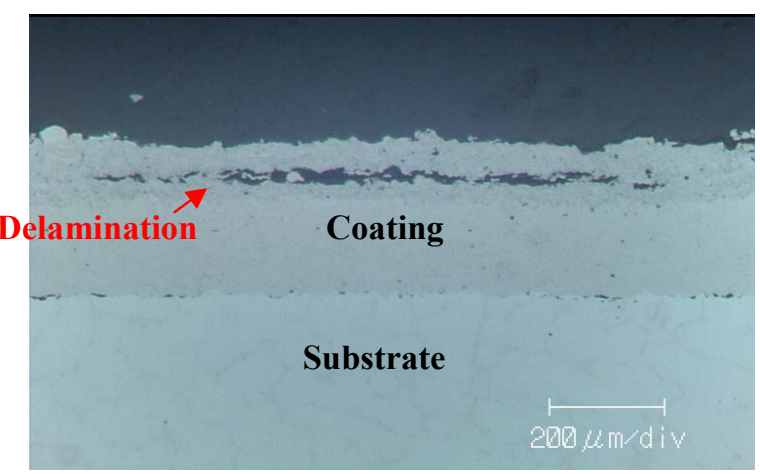

(b) Delamination in thermally sprayed coating

Fig. 2 Example of delamination of thermally sprayed coating (coating C)

A microhardness indenter with a load of $98 \mathrm{~N}$ was used to form precracks as shown in Fig 3. The specimens were heated in a furnace to $1273 \mathrm{~K}$ then held at this temperature for $100 \mathrm{~h}$ to promote the oxidation of $\mathrm{MoSi}_{2}$ so that we could examine the self-repair effect. The coating surface was examined by SEM, and X-ray diffraction analysis was used to identify the compounds formed near the precracks.

\section{Results and discussion}

\subsection{Thermal cyclic resistance}

The results for coating durability obtained by the thermal cyclic test are shown in Table 2 . 
For the conventional duplex TBC (coating C) with the NiCrAlY bond coating and YSZ top layer, delamination of the coating occurred after 20 thermal cycles. On the other hand, in coating $\mathrm{D}$ with an intermediate composite layer of $\mathrm{MoSi}_{2}$ and NiCrAlY, no delamination occurred even after 60 thermal cycles. This observation indicates that the introduction of the composite layer of $\mathrm{MoSi}_{2}$ and NiCrAlY between the bond coating and the YSZ layer in the conventional TBC system considerably improves the durability of TBCs. However, delamination was observed for coatings A, B and $\mathrm{E}$ after only one thermal cycle. In the case of coatings A and B, delamination occurred at the interface between the intermediate layer and the bond coating.

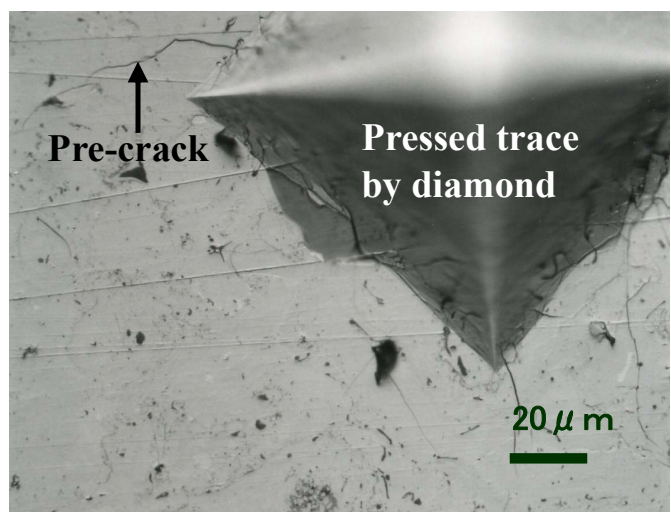

Fig. 3 Appearance of a precrack on a coated surface formed using an indenter under a load of $98 \mathrm{~N}$

Moreover, in the case of coating E, which has no intermediate layer, delamination took place at the interface between the top coating and the bond coating.

The thermal cyclic test results clearly indicated that coating $\mathrm{D}$ was more durable than the duplex coating. Furthermore, for coatings $\mathrm{A}$ and $\mathrm{B}$, which has a porous microstructure prepared by APS, delamination occurred after one thermal cycle even though these coatings contained an intermediate composite layer of $\mathrm{MoSi}_{2}$. Therefore, the preparation method for the intermediate composite layer significantly affects the durability of triple-layered TBCs. Accordingly, the morphology of the compounds resulting from the oxidation of $\mathrm{MoSi}_{2}$ in both APS and LPPS composite coatings was examined. Both the APS coating and the LPPS coating were oxidized by heating to $1273 \mathrm{~K}$ and holding at this temperature for $72 \mathrm{~h}$ before being slowly cooled to room temperature. The phases resulting from the oxidation of the coating were identified by X-ray diffraction analysis.

Table 2 Fatigue test results

\begin{tabular}{|c|c|c|c|c|c|}
\hline Materials & Coating A & Coating B & Coating $\mathrm{C}$ & Coating D & Coating E \\
\hline $\begin{array}{c}\text { Cycles } \\
\text { to failure }\end{array}$ & 1 & 1 & 20 & $\begin{array}{c}60 \\
\text { (No failure) }\end{array}$ & 1 \\
\hline $\begin{array}{l}\text { Location } \\
\text { of failure }\end{array}$ & $\begin{array}{c}\text { Interface } \\
\text { between the } \\
\text { intermediate } \\
\text { layer and the } \\
\text { bond coating }\end{array}$ & $\begin{array}{c}\text { Interface } \\
\text { between the } \\
\text { intermediate } \\
\text { layer and the } \\
\text { bond coating }\end{array}$ & $\begin{array}{c}\text { Interface } \\
\text { between the } \\
\text { top coating } \\
\text { and the bond } \\
\text { coating }\end{array}$ & - & $\begin{array}{c}\text { Interface } \\
\text { between the } \\
\text { top coating } \\
\text { and the bond } \\
\text { coating }\end{array}$ \\
\hline
\end{tabular}

The Formation of a $\mathrm{Mo}_{5} \mathrm{Si}_{3}$ phase was observed in the coating prepared by APS. The formation of $\mathrm{Mo}_{5} \mathrm{Si}_{3}$ possibly occurs through the oxidation of $\mathrm{MoSi}_{2}$ during spraying by the reaction

$5 \mathrm{MoSi}_{2}+7 \mathrm{O}_{2} \rightarrow \mathrm{Mo}_{5} \mathrm{Si}_{3}+7 \mathrm{SiO}_{2}$. $\quad----(1)$

Since the silicon content in $\mathrm{Mo}_{5} \mathrm{Si}_{3}$ is lower than that in $\mathrm{MoSi}_{2}$, the amount of $\mathrm{SiO}_{2}$ resulting from the oxidation of $\mathrm{Mo}_{5} \mathrm{Si}_{3}$ is very limited. As a result, only porous $\mathrm{SiO}_{2}$ was present in the coating ${ }^{(5)}$. Therefore, when $\mathrm{Mo}_{5} \mathrm{Si}_{3}$ is formed during the deposition of the intermediate layer, a dense protective coating of $\mathrm{SiO}_{2}$ cannot be formed within the cracks 
resulting from the thermal strain. In this case, substantial amounts of oxygen diffuse through the intermediate layer and oxidize the bond coating. With the oxidation of the $\mathrm{NiCrAlY}$ bond coating, the $\mathrm{TGO}\left(\mathrm{Al}_{2} \mathrm{O}_{3}\right.$ layers $)$ formed along the interface between the intermediate layer and the bond coating becomes thick. The formation of a thick TGO induces a volume increase ${ }^{(6)}$, which subsequently leads to coating delamination along the TGO. This is probably one of the reasons for the reduction in the resistance to thermal cycles of the coatings. Furthermore, the formed $\mathrm{Mo}_{5} \mathrm{Si}_{3}$ phase transforms from the $\beta$ phase (a hexagonal phase) to the $\alpha$ phase (a cubic phase) at about $950 \mathrm{~K}$ during cooling in the thermal cyclic test. The phase transformation also leads to an increase in volume ${ }^{(7)}$. Therefore, the coating delamination after only one thermal cycle may have resulted from this phase transformation.

When LPPS is employed to deposit the intermediate composite layer, a uniform composite layer of $\mathrm{MoSi}_{2}$ is obtained. Since LPPS is carried out in an inert atmosphere, the formation of $\mathrm{Mo}_{5} \mathrm{Si}_{3}$ due to oxidation during spraying is avoided. Dense $\mathrm{SiO}_{2}$ is formed at above $800 \mathrm{~K}$ following the reaction given by equation (2). Because $\mathrm{MoO}_{3}$ is evaporative, the resulting oxide consists of only of $\mathrm{SiO}_{2}{ }^{\left({ }^{(8)}\right.}$.

$2 \mathrm{MoSi}_{2}+7 \mathrm{O}_{2} \rightarrow 2 \mathrm{MoO}_{3}+4 \mathrm{SiO}_{2}$

Therefore, for coating D, the cracks formed in the intermediate layer during the thermal cyclic test were sealed by a protective $\mathrm{SiO}_{2}$ coating and the oxidation of the NiCrAlY bond coating was prevented. As a result, the thermal cyclic resistance was improved with the introduction of the LPPS intermediate layer. The parabolic oxidation rate constant of the $\mathrm{MoSi}_{2}$ coating at $1773 \mathrm{~K}^{(7)}$ ranges from $10^{-10}$ to $10^{-11} \mathrm{~kg}^{2} \mathrm{~m}^{-4} \mathrm{~s}^{-1}$. This rate constant is comparable to that of alumina grown at $1300 \mathrm{~K}{ }^{(7)}$. These results suggest that $\mathrm{MoSi}_{2}$ has greater oxidation resistance at higher temperature.

\subsection{Self-repair of the precracks}

The above results suggest that it is possible for the $\mathrm{SiO}_{2}$ resulting from the oxidation of $\mathrm{MoSi}_{2}$ to seal cracks and pores. Figure 4 shows the surface morphology of the sample oxidized at $1273 \mathrm{~K}$ for $100 \mathrm{~h}$. The precracks formed on the $\mathrm{MoSi}_{2}$ coating surface are shown in Fig. 4(a). EPMA images of Mo and Si near the crack tips on the $\mathrm{MoSi}_{2}$ coating surface are shown in Figs. 4(b) and 4(c), respectively. Mo is mainly present in the coating matrix and $\mathrm{Si}$ is mainly present in the open cracks. $\mathrm{O}$ is generally present because the $\mathrm{MoSi}_{2}$ coating surface was oxidized.

The mechanism of coating delamination in the conventional duplex TBC (coating $\mathrm{C}$ ) is schematically shown in Fig. 5. Oxygen atoms from the atmosphere penetrate YSZ mainly through cracks and pores to reach the bond coating and oxidize NiCrAlY at a high temperature. As a result, TGO $\left(\mathrm{Al}_{2} \mathrm{O}_{3}\right.$ layers $)$ is formed at the interface between the top coating and the bond coating. With the growth of TGO, the brittleness is increased and the thermal stress within the coating also increased. Accordingly, coating delamination occurs along the $\mathrm{TGO}^{(3)}$. A dense $\mathrm{SiO}_{2}$ phase is formed as a result of the oxidation of $\mathrm{MoSi}_{2}$ in the intermediate layer in the triple-layered TBCs. Some $\mathrm{SiO}_{2}$ is formed at the interface between the top coating and the intermediate layer, but the majority is formed in spaces such as cracks and pores in the intermediate layer, which seals the cracks and pores in the coating. The self-repair mechanism is schematically shown in Fig. 6. Case I shows the morphology of the cracks initiated in the direction parallel to the interface between the bond coating and the intermediate layer ${ }^{(9)}$. The cracks are induced by compressive thermal stress resulting from the difference between the expansion coefficients of the bond coating and the intermediate layer. 

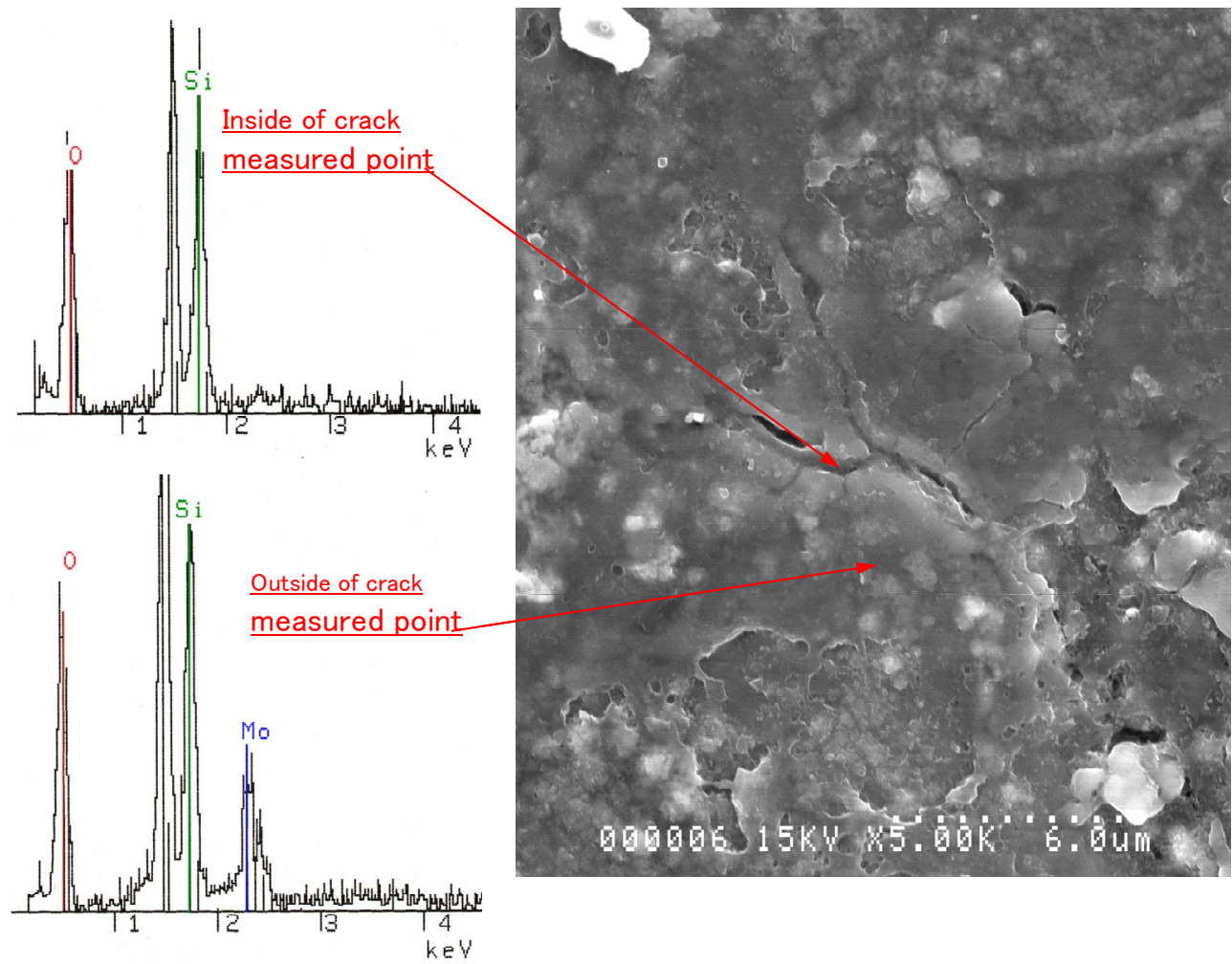

Fig. 4 SEM image of open crack and results of EDX analysis of Mo and $\mathrm{Si}$ in the vicinity of open crack

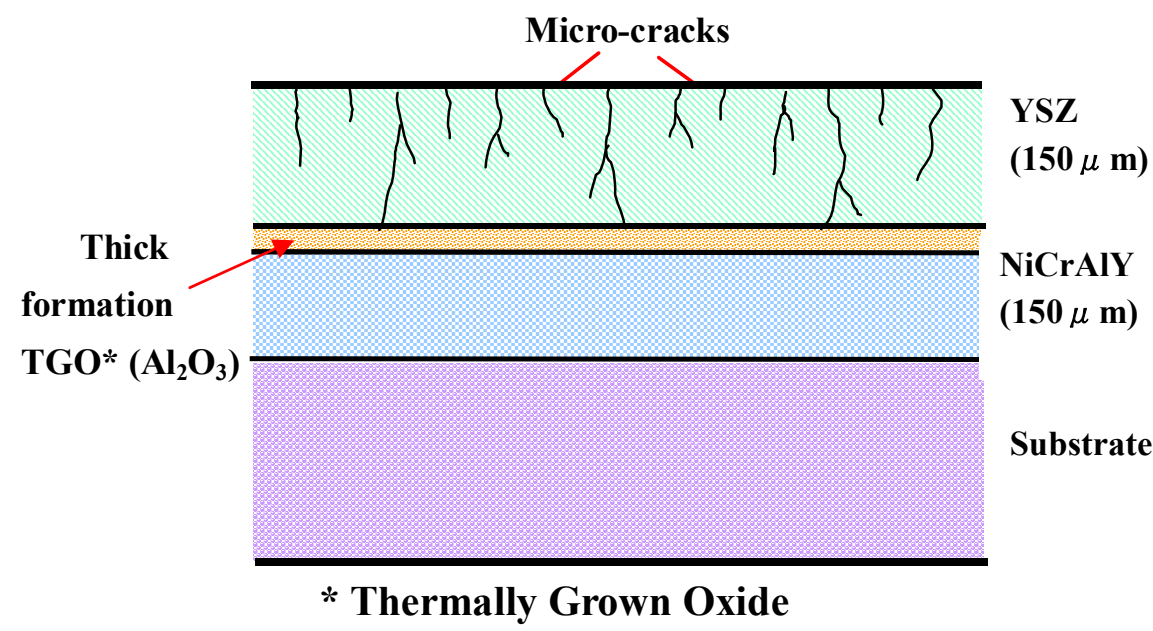

Fig. 5 Schematic diagram of proposed delamination mechanism of conventional sprayed coatings (coating $\mathbf{C}$ )

Case II shows the propagation of existing longitudinal cracks toward the intermediate layer under the tensile stress induced by the thermal cycle ${ }^{(10)}$. In both cases, the reaction expressed by equation $^{(2)}$ takes place in the intermediate layer at a high temperature, and a dense protective $\mathrm{SiO}_{2}$ coating is formed through the oxidation of $\mathrm{MoSi}_{2}$. The $\mathrm{SiO}_{2}$ coating is formed inside both cracks and pores and prevent oxygen diffusion from the atmosphere and penetration to the bond coating. Oxygen from the atmosphere can also penetrate through the coating matrix as well as through the cracks and pores. However, the flux of oxygen 
Case I

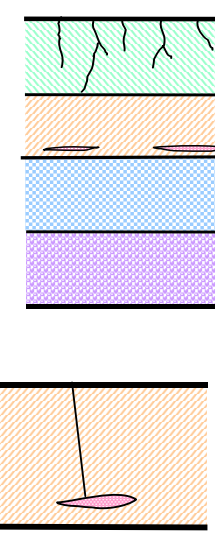

Case II

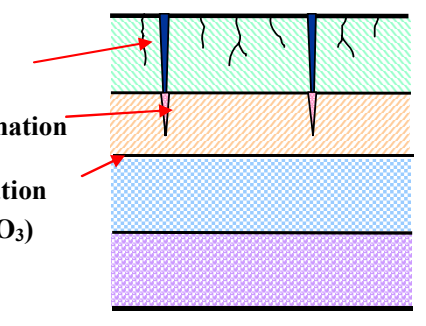

$\mathrm{YSZ}\left(\mathrm{ZrO}_{2}+\mathrm{Y}_{2} \mathrm{O}_{3}\right)$

(150 $\mu$ m)

$\mathrm{MoSi}_{2}+\mathrm{NiCrAIY}$

$(100 \mu \mathrm{m})$

NiCrAIY $\backslash(150 \mu$ m)

Substrate

$-\mathrm{SiO}_{2}$ (formed mainly in the cracks and pores)

$\mathrm{MoSi}_{2}$ layer $2 \mathrm{MoSi}_{2}+7 \mathrm{O}_{2} \rightarrow 2 \mathrm{MoO}_{3}+4 \mathrm{SiO}_{2}$

(Evaporation)

(formation in

the cracks and pores)

Fig. 6 Schematic diagrams of proposed self-repair mechanism of sprayed coatings for cases I and II (coating D)

penetrating through the matrix is considered to be less than $1 / 10$ of that through cracks and pores. Thus the majority of oxygen is through to penetrate to the bond coating through cracks and pores ${ }^{(11)}$. Therefore, by sealing the cracks and pores with $\mathrm{SiO}_{2}$ resulting from the oxidation of $\mathrm{MoSi}_{2}$, the oxidation of the bond coating is prevented. The microstructure that prevents the bond coating from oxidation is shown in Fig. 7. The prevention of the bond coating from oxidation improves the thermal cyclic performance of the triple-layered TBCs. Also, the reduction of the gradient resulting from the difference between thermal expansion coefficients of the top coating and the bond coating upon introducing the intermediate layer improves the thermal cyclic performance.

Thermal barrier property of each specimen is same temperature level of about $100^{\circ} \mathrm{C}$. It is noticed that thickness of coating has an effect on a delamination lifetime. And it is noticed that an oxidation occurrs between the top coating and the intermediate layer.

\section{Summary}

A $\mathrm{MoSi}_{2}$-containing composite was introduced as an intermediate layer in conventional duplex TBC systems to create triple-layered TBCs in order to clarify the possibility of preventing the oxidation of the MCrAlY bond coating and improve the thermal cyclic performance. The results obtained are summarized as follows.

(1) The thermal cyclic performance of coating $\mathrm{D}$ with a LPPS-deposited $\mathrm{MoSi}_{2}$ and $\mathrm{NiCrAlY}$ composite intermediate layer was superior to that of the conventional duplex $\mathrm{TBC}$, coating $\mathrm{C}$, under the test conditions employed in the present investigation.

(2) $\mathrm{The}_{\mathrm{MoSi}}$ phase in the intermediate layer of coating $\mathrm{D}$ formed $\mathrm{SiO}_{2}$ after oxidation. The formed $\mathrm{SiO}_{2}$ sealed the cracks and pores resulting from thermal stress during sprayed coating. The penetration of oxygen from the atmosphere mainly takes place through the cracks and pores, and the sealing of these racks and pores by the formation of a $\mathrm{SiO}_{2}$ coating prevents oxidation of the bond coating. Therefore, the formation of TGO is prevented, which leads to significant improvement of the thermal cyclic performance of coating D. Also, the reduction of the gradient resulting from the difference between the expansion coefficients of the top coating and the bond coating upon introducing the intermediate layer improves the thermal cyclic performance. 


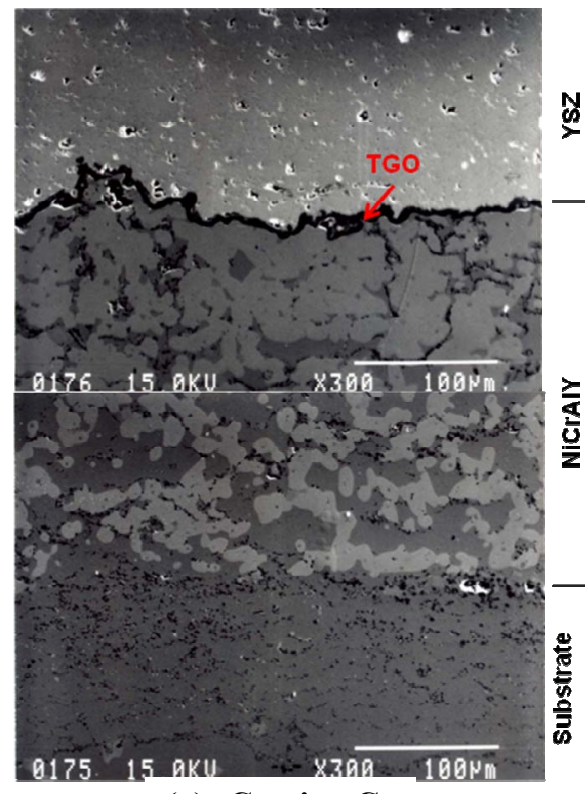

(a) Coating $\mathbf{C}$

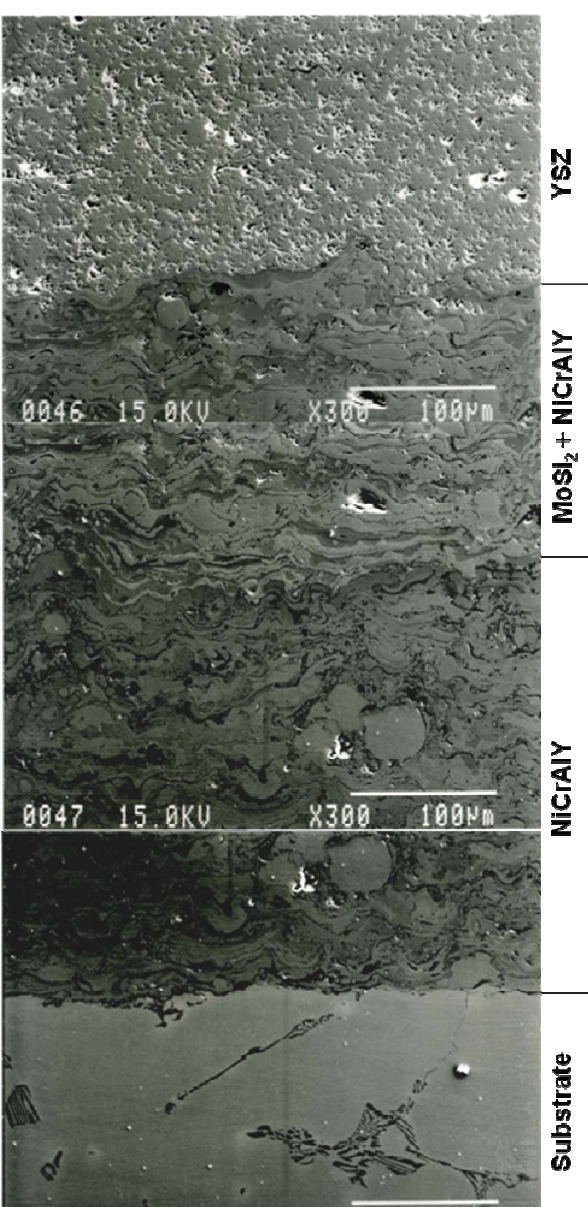

(b) Coating D

Fig. 7 Cross-sectional micrographs of the sprayed coating after oxidation test for $100 \mathrm{~h}$

\section{References}

(1) T. Okamoto, "Oxidation and Corrosion-Resistant Coating for Gas Turbine Engine", Kawasaki Juko Review, Vol.112, 1992, pp.1-7 (in Japanese).

(2) K. Fujiyama, "The Structure and Materials of Gas Tubines", Journal of Zairyou Kagaku, Vol.34, No.2, 1997, pp.6-12. (in Japanese).

(3) T. Kato, K. Ogawa and T. Shoji, "Development of Thermal Barrier Coatings for Enhancement of Delamination Resistant Property", Journal of Japan Thermal Spraying Society, Vol.39, No.2, 2002, pp.52-57 (in Japanese).

(4) S. M. Taomien and J. D. Dahl, "Cyclic Oxidation Testing of Molybdenum Protected by Silicide Coatings", Journal of Less-Common Metals, Vol.81, 1981, pp.249-260.

(5) E. W. Lee, J. Cook, A. Khan and R. Mahapatra, "The Oxidation Resistance of $\mathrm{MoSi}_{2}$ Coating on Niobium Alloys", Proceedings of International Thermal Spray Conference, 1992, pp.865-870.K.

(6) M. Yoshiba, "Environment-Induced Degradation in High Temperature Coating System", Journal of Zairyo-to-Kankyo, Vol.48, No.3, 1999, pp.135-143 (in Japanese).

(7) K. Sonoya, S. Tobe and S. Kitahara, "New Technology of Thermal Barrier Coating", Journal of Haikan-Gijutu, Vol.42, No.2, 2000, pp.35-37 (in Japanese).

(8) K. Kurokawa and S. Taniguchi, "High Temperature Oxidation Resistance of a Range of Intermetallics”, Journal of Zairyo-to-Kankyo, Vol.48, No.3, 1999, pp.117-122 (in Japanese). 
(9) N. Zacchetti, "High Temperature Oxidation Resistant Properties of Low Pressure Plasma Sprayed $\mathrm{MoSi}_{2}$ Coating on Niobium Alloys", Proceedings of International Thermal Spray Conference, 1992, pp.865-870.

(10) Y. Mutoh, J. A. Haynes, W. R. Canon and M. K. Ferber, "Failure Characteristics of Zirconia-Coated Structural Steel Under Thermal Cycling and Thermal Shock", Quarterly Journal of Japan Welding Society, Vol.7, No.2, 1989, pp.208-213 (in Japanese).

(11) M. Fukumoto, T. Ueda and I. Okane, "Protecting Properties of Oxidation Resistant Plasma Sprayed $\mathrm{MoSi}_{2}$ Coating”, Journal of Japan Thermal Spraying Society, Vol.30, No.4, 1993 , pp.163-168 (in Japanese). 